\title{
Progression of Fibrosis in Usual Interstitial Pneumonia: Serial Evaluation of the Native Lung after Single Lung Transplantation
}

\author{
Aleksandar Grgic a,c Henning Lausberg ${ }^{d}$ Marc Heinrich ${ }^{c, f}$ Jochem Koenig ${ }^{e}$ \\ Michael Uder ${ }^{c, f}$ Gerhard W. Sybrecht $^{\mathrm{b}}$ Heinrike Wilkens ${ }^{\mathrm{b}}$ \\ ${ }^{a}$ Klinik für Nuklearmedizin, ${ }^{b}$ Medizinische Klinik und Poliklinik, Innere Medizin V, ${ }^{c}$ Klinik für Diagnostische und \\ Interventionelle Radiologie, ${ }^{d}$ Chirurgische Klinik, Abteilung Thorax-, Herz- und Gefässchirurgie und \\ e Institut für Medizinische Biometrie, Epidemiologie und Medizinische Informatik, Universitätsklinikum des \\ Saarlandes, Homburg/Saar, und ${ }^{\mathrm{f} I n s t i t u t ~ f u ̈ r ~ D i a g n o s t i s c h e ~ R a d i o l o g i e, ~ F r i e d r i c h-A l e x a n d e r-U n i v e r s i t a ̈ t, ~}$ \\ Erlangen/Nürnberg, Deutschland
}

\section{Key Words}

Idiopathic pulmonary fibrosis - Lung transplantation, single $\cdot$ Computed tomography, high resolution . Immunosuppressive therapy · Cyclosporin A

\begin{abstract}
Background: Idiopathic pulmonary fibrosis (IPF) is a progressive disease with a poor prognosis. Usual interstitial pneumonia (UIP) is the histopathological pattern identifying patients with the clinical entity of IPF. Despite aggressive immunosuppressive therapy the clinical course is usually dismal. For selected patients only lung transplantation improves prognosis and quality of life. After lung transplantation patients often receive a potent cyclosporine-based immunosuppressive therapy. Some reports suggest that cyclosporine has the potential to prevent progression of fibrosis. Objective: In patients with single lung transplantation (sLTx) for UIP we evaluated the effect of cyclosporine-based immunosuppressive therapy on progression of fibrosis using a high-resolution computed tomography (HRCT) scoring system. Methods: This retrospective observational study included 13 patients (24-64 years old) with histologically confirmed UIP who had HRCT scans preceding and following sLTX and who survived at least 6 months after sLTX. All pa-
\end{abstract}

\section{KARGER}

Fax +41613061234 E-Mail karger@karger.ch www.karger.com
(C) 2007 S. Karger AG, Basel

$0025-7931 / 08 / 0762-0139 \$ 24.50 / 0$

Accessible online at:

www.karger.com/res tients were initially treated with cyclosporin A, prednisone and azathioprine. Three radiologists analyzed HRCT scans by setting a score regarding fibrosis [fibrosis score (FS); range 0-5 for each lobe] and ground-glass opacity [ground-glass score (GGS); range $0-5$ for each lobe]. A comparison of serial changes (interval: 12-96 months posttransplant, 2-4 HRCT examinations/patient) was performed with the sign test. $\boldsymbol{R e}$ sults: Mean pretransplant FS and GGS of the nontransplanted lung were 1.80 and 1.61 , respectively. Comparing pre- and posttransplant HRCT scans, mean lung FS significantly increased $(0.35 \pm 0.15$ year; $p=0.00024)$, while GGS tended to decrease $(0.06 \pm 0.26 /$ year; $p=0.5)$. Conclusion: $A$ cyclosporin A based triple immunosuppressive regimen following sLTX does not seem to prevent progression of the fibrotic changes of the native lung in patients with IPF.

Copyright $\odot 2007$ S. Karger AG, Basel

\section{Introduction}

Idiopathic pulmonary fibrosis (IPF) is a progressive disease of the lung parenchyma characterized by varying degrees of interstitial fibrosis [1,2]. A recent international consensus statement concluded that usual interstitial pneumonia (UIP) is the histopathological pattern identi- 
fying patients with the clinical entity of IPF [2]. The clinical course is dismal in most patients, usually beginning with exertional dyspnea [2]. Impaired gas exchange as well as a restrictive pattern in pulmonary function tests and peripheral basal bilateral reticular pulmonary opacities on chest radiographs [3] are key clinical features of IPF. Even in the absence of a complicating disease such as coronary artery disease, infections, severe pulmonary hypertension and bronchogenic carcinoma, the median survival is less than 3 years [4]. At present, there is no good evidence that would definitely support the routine use of any therapeutic agent to treat IPF [4-10]. Because IPF is a relatively rare disease (7-10 cases/100,000/year), randomized, placebo-controlled therapeutic studies are difficult to perform [11]. Although many investigators have underscored intra-alveolar inflammation as a cause, anti-inflammatory agents and immune modulators have proved to be minimally effective in limiting alveolitis and modifying the natural course of the disease [12]. Corticosteroids are commonly used as a first-line treatment in patients with IPF despite the lack of proven efficacy [6, $13,14]$. Less than $30 \%$ of patients show partial and transient response $[2,5,10,15]$. The combination of azathioprine and prednisone was proposed as standard therapy by the American Thoracic Society (ATS) and European Respiratory Society (ERS) Statement $[4,16]$ despite very limited evidence. Treatment with interferon- $\gamma-1 b$ has not affected progression-free survival, pulmonary function, or quality of life [17]. N-Acetylcysteine [18] and pirfenidone [19] may have some beneficial effects, but additional large clinical trials are needed to confirm their usefulness.

Results regarding the effect of cyclosporin $\mathrm{A}$ on the progression of the IPF are controversial [20-23]. The combination of cyclosporin $\mathrm{A}$, corticosteroids, and azathioprine is most commonly used in patients after lung transplant for immunosuppression [24]. In this paper we evaluated the response of the native lung to a cyclosporin A-based immunosuppressive regimen in patients with histologically proven UIP after single lung transplantation (sLTx) using a high-resolution computed tomography (HRCT) scoring system.

\section{Patients and Methods}

\section{Study Subjects}

From August 1995 to January 200422 patients underwent unilateral lung transplantation for diffuse interstitial lung disease. In 17 patients UIP was histologically confirmed. The diagnosis of IPF was made by exclusion of other known causes of interstitial lung disease, characteristic abnormalities on HRCT scans (bibasilar subpleural honeycombing, thickened intralobular septa, traction bronchiectasis and minimal ground-glass opacities), abnormal pulmonary function studies showing restriction and impaired gas exchange according to the criteria of the ATS/ERS consensus classification [25]. Four patients were excluded from the study because computed tomography (CT) scans were not available. Only patients who had at least one HRCT up to 6 months before and one 6 months after sLTx and who received cyclosporin A-based immunosuppression entered the study. CT scans were not used, if the patients had an apparent complication such as pneumonia or edema, or if only thick-collimated (more than 3mm slice thickness) conventional or helical CT scans were available.

As the present study is a retrospective observational study that includes a review of the imaging studies, and clinical and pathological data, neither institutional board approval nor informed consent is required by the national law in our country.

\section{HRCT Scans}

The HRCT scans were performed with 1- to $1.5-\mathrm{mm}$ section thickness at $10-\mathrm{mm}$ intervals in full inspiration, a $512 \times 512$ reconstruction matrix, a high-spatial-frequency reconstruction algorithm, 120-140 kV, and 160-210 mAs, without injection of contrast material. Scans were obtained with a Hi Speed Scanner (GE Medical Systems, Milwaukee, Wisc., USA), Somatom Plus (Siemens, Erlangen, Germany), and MX 8000 (Philips Medical Systems, Best, The Netherlands). The HRCT scans were obtained with different lung window settings (window level -500 to -700 $\mathrm{HU}$ and window width 1,500-1,600 HU). Soft-tissue settings were not obtained routinely.

\section{HRCT Scoring}

All of the HRCT images were reviewed by three radiologists working together as a team. A final decision was made by consensus. The reviewers were aware of the diagnosis of IPF. Pretransplantation scans were reviewed without knowledge of which lung was removed during the transplantation procedure. For analysis of posttransplant HRCT scans the radiologists were blinded to the findings on the pretransplant HRCT scans or the time after transplantation. A fibrosis score (FS) and ground-glass score (GGS) were used as previously described by Gay et al. [8]. Each lobe of the native lung was separately scored on a scale of $0-5$ for the presence of both ground-glass opacity and interstitial abnormalities which include septal thickening and honeycombing according to the scheme described in table 1 . The lingula was scored as a separate lobe. After each lobe was scored individually, an average score for all lobes was obtained and used for the statistical analysis.

Statistical Analysis

For the statistical analysis SPSS statistical software was used (SPSS 11, SPSS Inc., Chicago, Ill., USA). The quantitative average scores (FS and GGS) were analyzed as follows: slopes were determined for each patient by fitting linear least square regression lines to individual posttransplantation time courses. Resulting slopes were analyzed by the sign test. Only slopes from the last pretransplatation HRCT (up to 6 months before transplantation) and those from posttransplatation HRCTs were analyzed (table 4). A p $<0.05$ was considered significant. 


\section{Results}

Thirteen patients ( 5 female, 8 male, $24-64$ years old) fulfilled our selection criteria and formed the study population. Patient data are shown in table 2. In 4 patients sLTx was performed on the right, in 9 patients on the left side. Our patient population was affected by severe restrictive lung function pattern with a forced expiratory volume in $1 \mathrm{~s}$ of $45.2 \pm 14 \%$ pred. (range 26-67), vital capacity of $38.2 \pm 12 \%$ pred. (range $22-57$ ), total lung capacity of $44.7 \pm 9 \%$ pred. (range 33-59). The average duration between establishing the diagnosis and sLTx was $42 \pm 22$ months (range 14-79 months). All 13 patients underwent sLTx operation and standard postoperative management and were treated with an immunosuppressive regimen consisting of prednisone, azathioprine and cyclosporin A. In 2 patients this regimen was changed to tacrolimus and mycophenolate mofetil after 48 and 54 months, respectively, due to the development of bronchiolitis obliterans syndrome grade II.

Prednisone dosage was $1 \mathrm{mg} / \mathrm{kg}$ initially and tapered to $7.5 \mathrm{mg}$ at the end of the first year. Azathioprine was dosed at 1-2 $\mathrm{mg} / \mathrm{kg}$ based on each patient's white blood cell count. Cyclosporin A was dosed to achieve an initial trough serum level of $350 \mathrm{mg} / \mathrm{ml}$ and tapered down to a trough level of $250-200 \mathrm{mg} / \mathrm{ml}$ at the end of the first year and to $100-200 \mathrm{mg} / \mathrm{ml}$ after 3 years according to organ function and renal function.

HRCT examinations were obtained $42 \pm 26$ days prior to sLTx (range 88-7 days). After sLTx the follow-up period ranged from 12 to 96 months (mean $42 \pm 27$ months). Hard copies of 39 HRCT examinations were available. In each patient 2-4 examinations were done (tables 2, 3).

The mean lung FS and GGS in the nontransplanted lung on the last pretransplantation HRCT scan were 1.80 $( \pm 0.27)$ and $1.61( \pm 0.45)$, respectively (table 4$)$.

The ground-glass opacity was improved in 6 patients, stable in 4 patients and worse in 3 patients. When comparing the serial changes in pre- and posttransplant HRCT scans the average GGS tended to decrease $(-0.06$ $\pm 0.26 /$ year $)$; this, however, was not significant $(\mathrm{p}=0.5)$. No relationship between rejection history and change in GGS could be detected.

All patients showed an increase in the extent of the fibrotic changes after sLTx (fig. 1, 2). The average score regarding fibrotic changes increased in all patients $(\mathrm{p}=$ 0.00024 ) (fig. 3). The mean increase of the score was 0.35 $( \pm 0.15) /$ year (tables 3,4$)$.

Progression of Fibrosis after Single Lung Transplantation
Table 1. Usual interstitial pneumonia: HRCT scoring system [adapted from 8]

GGS

$0 \quad$ No alveolar disease

1 Ground glass opacity involving $<5 \%$ of the lobe (minimal, but not normal)

2 Ground glass opacity involving up to $25 \%$ of the lobe

3 Ground glass opacity involving 25-49\% of the lobe

4 Ground glass opacity involving $50-75 \%$ of the lobe

5 Ground glass opacity involving $>75 \%$ of the lobe

FS

$0 \quad$ No interstitial disease

1 Interlobular septal thickening; no discrete honeycombing

2 Honeycombing (+/- septal thickening) involving up to $25 \%$ of the lobe

3 Honeycombing (+/- septal thickening) involving 25-49\% of the lobe

4 Honeycombing (+/- septal thickening) involving 50-75\% of the lobe

5 Honeycombing (+/- septal thickening) involving $>75 \%$ of the lobe

Table 2. Anthropometric data of patients

\begin{tabular}{lllllll}
\hline $\begin{array}{l}\text { Patient } \\
\text { No. }\end{array}$ & Sex & $\begin{array}{l}\text { Trans- } \\
\text { planted } \\
\text { lung side }\end{array}$ & $\begin{array}{l}\text { Age at } \\
\text { transplanta- } \\
\text { tion, years }\end{array}$ & $\begin{array}{l}\text { Follow-up } \\
\text { duration after } \\
\text { sLTx, months }\end{array}$ & $\begin{array}{l}\text { CTs } \\
\text { n }\end{array}$ & $\begin{array}{l}\text { CTs after } \\
\text { sLTx } \\
\text { n }\end{array}$ \\
\hline 1 & M & R & 39 & 60 & 3 & 1 \\
2 & M & R & 64 & 60 & 3 & 2 \\
3 & F & L & 59 & 22 & 4 & 3 \\
4 & F & L & 57 & 48 & 3 & 2 \\
5 & M & L & 48 & 20 & 3 & 2 \\
6 & M & L & 61 & 18 & 3 & 1 \\
7 & F & L & 38 & 24 & 2 & 1 \\
8 & M & L & 60 & 75 & 3 & 1 \\
9 & M & L & 47 & 52 & 3 & 2 \\
10 & M & L & 64 & 12 & 3 & 1 \\
11 & F & R & 35 & 96 & 3 & 2 \\
12 & M & L & 63 & 23 & 3 & 2 \\
13 & F & R & 24 & 46 & 3 & 1 \\
\hline
\end{tabular}

\section{Discussion}

Despite significant advances IPF remains a diagnostic and therapeutic challenge with a limited understanding of etiology and treatment options [26]. The rapid progressive nature of this disease restrains the development of effective preventive and therapeutic strategies [26]. Our study reports for the first time serial changes in HRCT scores over a longer follow-up period in a group of pa-

Respiration 2008;76:139-145 
Table 3. Average FS and GGS of all patients on the pretransplantation scans and after transplantation

\begin{tabular}{|c|c|c|c|}
\hline Patient & $\begin{array}{l}\text { Time before/after } \\
\text { sLTx, years }\end{array}$ & FS & GGS \\
\hline \multirow[t]{3}{*}{ Patient 1} & -1.5 & 1.95 & 2.1 \\
\hline & 0 & 2.67 & 2.5 \\
\hline & 5 & 3.66 & 3.84 \\
\hline \multirow[t]{3}{*}{ Patient 2} & 0 & 2 & 0 \\
\hline & 1 & 2.67 & 0 \\
\hline & 5 & 3.33 & 0 \\
\hline \multirow[t]{4}{*}{ Patient 3} & 0 & 1 & 1 \\
\hline & 1 & 1 & 1 \\
\hline & 2 & 2 & 1 \\
\hline & 3 & 2.33 & 1 \\
\hline \multirow{3}{*}{ Patient 4} & 0 & 2 & 1.67 \\
\hline & 2 & 2.67 & 0.33 \\
\hline & 4 & 3.33 & 0.33 \\
\hline \multirow[t]{3}{*}{ Patient 5} & 0 & 3 & 0 \\
\hline & 2 & 3.33 & 0 \\
\hline & 2.5 & 4 & 0 \\
\hline \multirow[t]{3}{*}{ Patient 6} & -2 & 1 & 2 \\
\hline & 0 & 2 & 1 \\
\hline & 2 & 2.67 & 0.67 \\
\hline \multirow[t]{2}{*}{ Patient 7} & 0 & 1.67 & 0.67 \\
\hline & 2 & 4 & 0 \\
\hline \multirow[t]{3}{*}{ Patient 8} & -5 & 1.33 & 3 \\
\hline & 0 & 0.33 & 2.33 \\
\hline & 7 & 4.13 & 0 \\
\hline \multirow[t]{3}{*}{ Patient 9} & 0 & 1.33 & 2.67 \\
\hline & 1 & 1.33 & 2.67 \\
\hline & 5 & 1.67 & 4.1 \\
\hline \multirow[t]{3}{*}{ Patient 10} & -1.5 & 2 & 1 \\
\hline & 0 & 3 & 1 \\
\hline & 1 & 3.33 & 1 \\
\hline \multirow[t]{3}{*}{ Patient 11} & 0 & 2.33 & 3 \\
\hline & 6 & 3.33 & 2.33 \\
\hline & 8 & 4 & 0 \\
\hline \multirow[t]{3}{*}{ Patient 12} & 0 & 1 & 1 \\
\hline & 1 & 1.33 & 1.67 \\
\hline & 2 & 1.67 & 0.67 \\
\hline \multirow[t]{3}{*}{ Patient 13} & -0.5 & 0.66 & 1 \\
\hline & 0 & 1 & 2.33 \\
\hline & 4 & 2 & 3 \\
\hline
\end{tabular}

Table 4. Overview of the FS and GGS results

\begin{tabular}{lllll}
\hline & Mean lung score & Change per year & Median & p value \\
\hline FS & $1.80 \pm 0.27$ & $0.35 \pm 0.15$ & 0.33 & 0.00024 \\
GGS & $1.61 \pm 0.45$ & $-0.06 \pm 0.26$ & 0.002 & 0.5 \\
\hline
\end{tabular}

${ }^{1}$ Mean lung score of the nontransplanted lung before transplantation. tients after unilateral lung transplantation. In our patients a combination of cyclosporin A, corticosteroids, and azathioprine did not prevent progression of fibrosis in the native lung.

Treatment with cyclosporin A was studied retrospectively in a small series of 13 patients after an acute exacerbation of IPF [20]. The authors concluded that cyclosporin A seemed to prevent reexacerbation of IPF [20]. In contrast to that report Alton et al. [27] followed up 7 patients who were treated with cyclosporin A after unsuccessful treatment with prednisolone and cyclophosphamide. Initially, these patients showed clinical and physiological improvement. However, further improvement was not remarkable and deterioration of the fibrosis occurred [27]. Lok et al. [21] reported improvement of IPF in 1 patient after sLTx with cyclosporin A therapy that was not sustained.

Our data confirm the results of Wahidi et al. [23], who retrospectively examined the response of native lung to immunosuppression in a small group of 5 patients after sLTx and found no effect on the progression of the disease. However, they had data on serial changes in only 2 patients and they used mainly conventional CT scans in the evaluation process, while we used only serial HRCT scans which have been shown to be better than conventional CT scans in the evaluation of patients with fibrotic lung disease and especially in predicting response to therapy $[2,8,25]$.

In our study findings of fibrosis (intralobular septal thickening and honeycombing) increased in the native lung after sLTx in serial evaluation of HRCT examinations in all 13 patients who underwent a cyclosporin Abased immunosuppressive regimen $(\mathrm{p}=0.00024)$. Our findings are similar to those reported in several studies in patients before lung transplantation [9, 28-31]. Although some investigators reported that the ground-glass opacities represent an ongoing fibrotic process, we found that the GGS did not correlate with the progression of fibrosis. This could be at least partly due to the difficulty to detect small changes in the lung parenchyma, as the scoring systems were divided only into 5 grades. However, with the use of finer classified scores we seemed to lose improved simplicity and reliability in the assessment of the FS and GGS. It is conceivable that the ground-glass opacities do not always represent cellular inflammation in the IPF population [32]. Nagao et al. [32] demonstrated that the UIP histology showed a greater paucity of bronchoalveolar lavage fluid lymphocytosis in the IPF patient group than in the UIP patient group with associated collagen vascular disease. In addition, most IPF patients in 
Fig. 1. a HRCT scan in a 48-year-old patient at the level of right middle lobe obtained 6 months before lung transplantation shows characteristic peripheral subpleural honeycombing, inter- and intralobular septal thickening as well as broncho- and bronchioloectasis (white arrowheads) involving up to $25 \%$ (FS of 2) of the middle lobe. Note that the groundglass opacity is a minor finding in the lower lobe $(G)$. b Two years after transplantation there is remarkable increase in fibrosis in the right middle lobe (FS of 4) but with only minor ground-glass component (arrowhead). Note the increased honeycombing in the lower lobe $(\mathrm{H})$.

Fig. 2. a HRCT in a 47-year-old patient at the level of the lingula a few days before lung transplantation shows areas of honeycombing (arrows) involving up to 50\% of the lobe (FS of 3). Subpleural areas of ground-glass opacity are present (GGS of 1) (arrowheads). b One year after lung transplantation marked progression of the fibrotic changes and FS of 5 involving more than $75 \%$ of the lobe (arrow) can be seen.
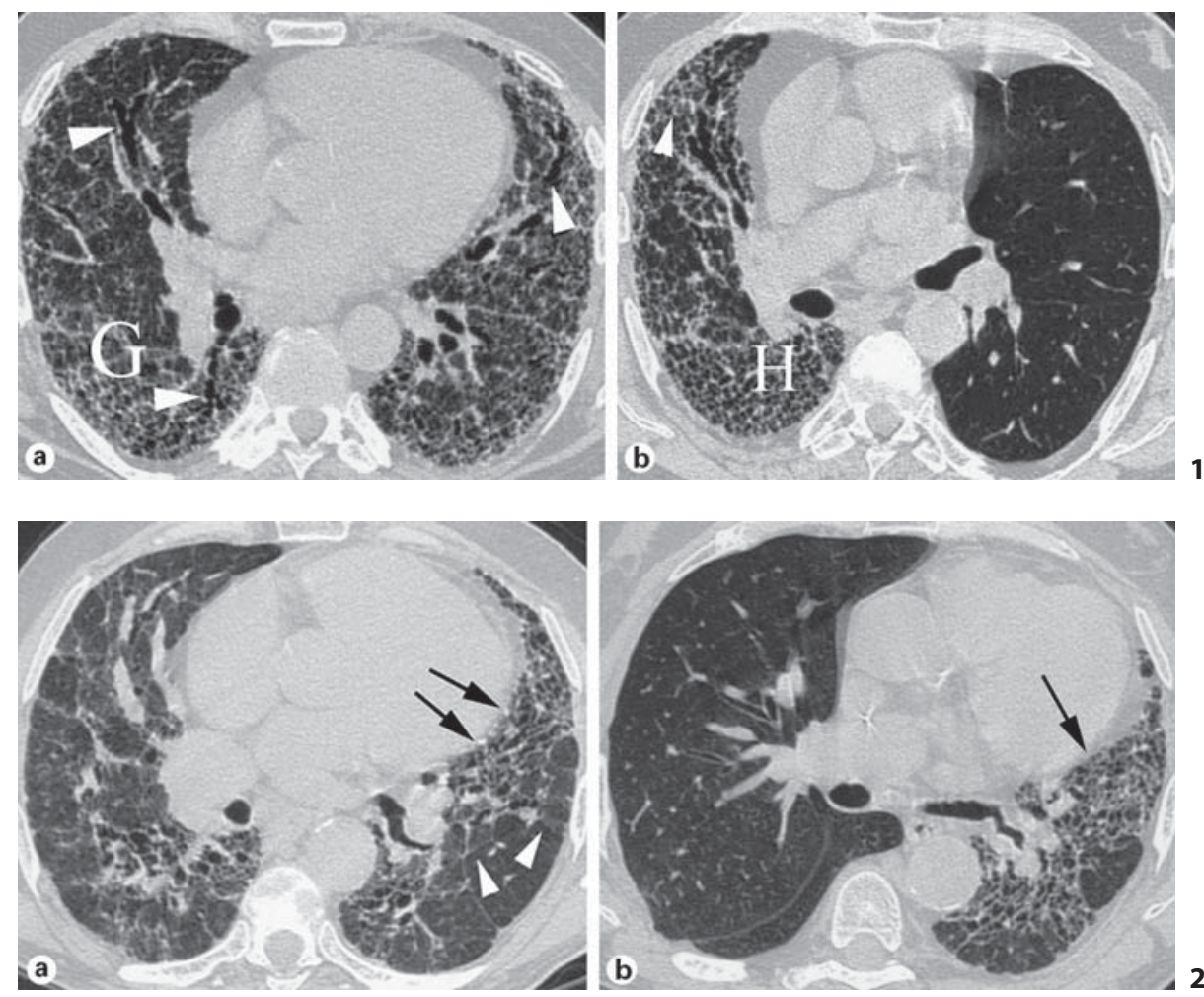

our group presented at later stages of the disease with advanced fibrotic changes, whereas ground-glass opacity was expected to be minimal.

However, our study has several limitations. There are intrinsic selection biases in the study population due to the retrospective nature of the study. Another limitation of our study is the small number of patients. The limited patient population, although representative of our clinics, might not reflect all patients with IPF after sLTx. In addition, our patients were self-selected, as all had to be fit enough for sLTx and all had to survive for at least 6 months after sLTx. This resulted in the selection of relatively young patients with IPF, which may not be representative for the typical population of patients with IPF.

Assessment of the FS of the native lung may be influenced by the difference in compliance between the native lung and the healthy allograft. The degree of expansion of the native lung at full inspiration after the transplantation probably would not be as great as it was prior to transplantation, leading to mediastinal shift, possibly with concomitant contraction of the native lung and overestimation of the FS. In all patients, however, in whom serial measurements were available, a clear increase in the FS was found with unchanged volumes of the transplanted

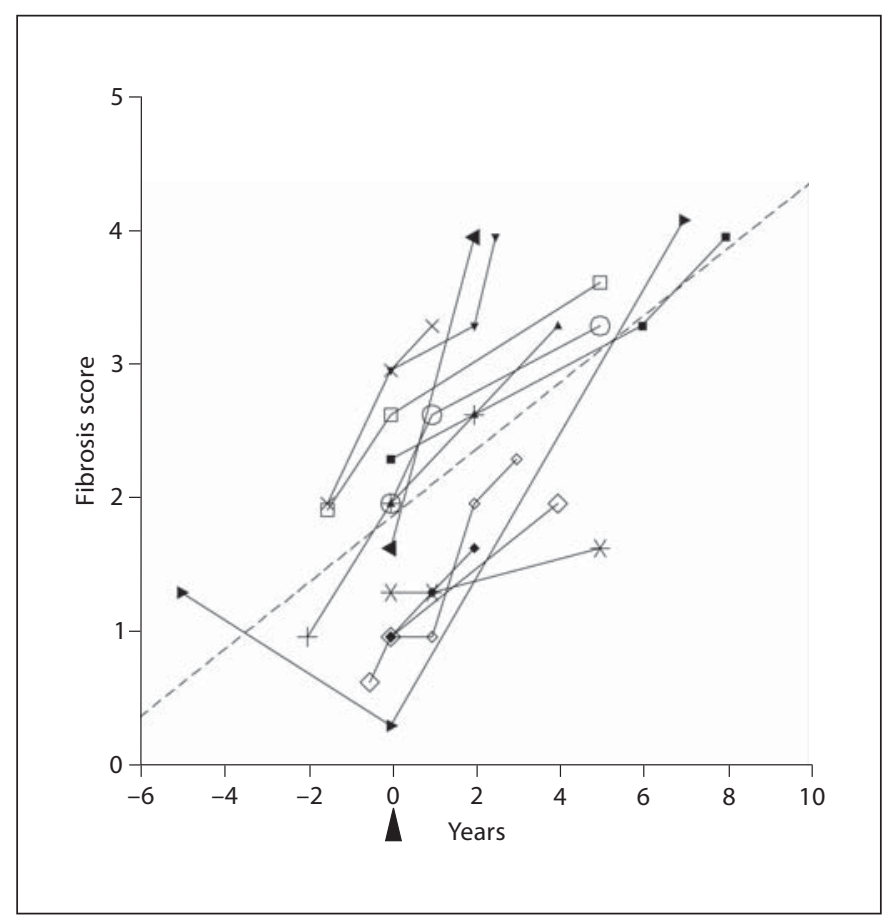

Fig. 3. Scatter diagram shows serial changes of the patients' FS. Time of the lung transplantation is indicated by the arrowhead. $---=$ Total population. 
lung, indicating that the deterioration was not simply due to the mediastinal shift, but to disease progression.

In conclusion, our study demonstrates for the first time serial changes of an ongoing fibrotic process in the native lung following sLTx indicating that a triple-drug immunosuppressive regimen consisting of corticosteroids, azathioprine and cyclosporin A does not seem to prevent progression of fibrosis. Investigations of alternative therapies directed towards the underlying pathophysiology in patients suffering from IPF are urgently needed to improve prognosis.

\section{Acknowledgements}

The authors would like to thank Professor Hans Joachim Schaefers and Professor Stephan Diederich for their valuable contribution and suggestions during the preparation of the manuscript.

\section{References}

1 White ES, Lazar MH, Thannickal VJ: Pathogenetic mechanisms in usual interstitial pneumonia/idiopathic pulmonary fibrosis. J Pathol 2003;201:343-354.

2 American Thoracic Society: Idiopathic pulmonary fibrosis: diagnosis and treatment. International consensus statement. American Thoracic Society (ATS), and the European Respiratory Society (ERS). Am J Respir Crit Care Med 2000;161:646-664.

3 Zompatori M, Bna C, Poletti V, Spaggiari E, Ormitti F, Calabro E, Tognini G, Sverzellati $\mathrm{N}$ : Diagnostic imaging of diffuse infiltrative disease of the lung. Respiration 2004;71:419.

4 Gross TJ, Hunninghake GW: Idiopathic pulmonary fibrosis. N Engl J Med 2001;345:517525 .

5 Johnston ID, Prescott RJ, Chalmers JC, Rudd RM: British Thoracic Society study of cryptogenic fibrosing alveolitis: current presentation and initial management. Fibrosing Alveolitis Subcommittee of the Research Committee of the British Thoracic Society. Thorax 1997;52:38-44

6 Hubbard R, Johnston I, Britton J: Survival in patients with cryptogenic fibrosing alveolitis: a population-based cohort study. Chest 1998;113:396-400.

7 Hubbard R, Johnston I, Coultas DB, Britton $\mathrm{J}$ : Mortality rates from cryptogenic fibrosing alveolitis in seven countries. Thorax 1996; 51:711-716.

8 Gay SE, Kazerooni EA, Toews GB, Lynch JP 3rd, Gross BH, Cascade PN, Spizarny DL, Flint A, Schork MA, Whyte RI, Popovich J, Hyzy R, Martinez FJ: Idiopathic pulmonary fibrosis: predicting response to therapy and survival. Am J Respir Crit Care Med 1998; 157:1063-1072.

9 Bjoraker JA, Ryu JH, Edwin MK, Myers JL, Tazelaar HD, Schroeder DR, Offord KP: Prognostic significance of histopathologic subsets in idiopathic pulmonary fibrosis. Am J Respir Crit Care Med 1998;157:199_ 203.
10 Walter N, Collard HR, King TE Jr: Current perspectives on the treatment of idiopathic pulmonary fibrosis. Proc Am Thorac Soc 2006;3:330-338.

11 Coultas DB, Zumwalt RE, Black WC, Sobonya RE: The epidemiology of interstitial lung diseases. Am J Respir Crit Care Med 1994;150:967-972.

12 Verma S, Slutsky AS: Idiopathic pulmonary fibrosis - new insights. N Engl J Med 2007; 356:1370-1372.

13 Douglas WW, Ryu JH, Schroeder DR: Idiopathic pulmonary fibrosis: impact of oxygen and colchicine, prednisone, or no therapy on survival. Am J Respir Crit Care Med 2000; 161:1172-1178.

14 Nagai S, Kitaichi M, Hamada K, Nagao T, Hoshino Y, Miki H, Izumi T: Hospital-based historical cohort study of 234 histologically proven Japanese patients with IPF. Sarcoidosis Vasc Diffuse Lung Dis 1999;16:209214.

15 Rudd RM, Haslam PL, Turner-Warwick M Cryptogenic fibrosing alveolitis. Relationships of pulmonary physiology and bronchoalveolar lavage to response to treatment and prognosis. Am Rev Respir Dis 1981;124: $1-8$.

16 Raghu G, Depaso WJ, Cain K, Hammar SP, Wetzel CE, Dreis DF, Hutchinson J, Pardee NE, Winterbauer RH: Azathioprine combined with prednisone in the treatment of idiopathic pulmonary fibrosis: a prospective double-blind, randomized, placebo-controlled clinical trial. Am Rev Respir Dis 1991; 144:291-296.

17 Raghu G, Brown KK, Bradford WZ, Starko K, Noble PW, Schwartz DA, King TE Jr: A placebo-controlled trial of interferon gamma-1b in patients with idiopathic pulmonary fibrosis. N Engl J Med 2004;350:125-133.
18 Demedts M, Behr J, Buhl R, Costabel U, Dekhuijzen R, Jansen HM, MacNee W, Thomeer M, Wallaert B, Laurent F, Nicholson AG, Verbeken EK, Verschakelen J, Flower CD, Capron F, Petruzzelli S, De Vuyst P, van den Bosch JM, Rodriguez-Becerra E, Corvasce $G$, Lankhorst I, Sardina M, Montanari M: High-dose acetylcysteine in idiopathic pulmonary fibrosis. N Engl J Med 2005;353: 2229-2242.

19 Azuma A, Nukiwa T, Tsuboi E, Suga M, Abe S, Nakata K, Taguchi Y, Nagai S, Itoh H, Ohi M, Sato A, Kudoh S: Double-blind, placebocontrolled trial of pirfenidone in patients with idiopathic pulmonary fibrosis. Am J Respir Crit Care Med 2005;171:1040-1047.

20 Inase N, Sawada M, Ohtani Y, Miyake S, Isogai S, Sakashita H, Miyazaki Y, Yoshizawa Y: Cyclosporin A followed by the treatment of acute exacerbation of idiopathic pulmonary fibrosis with corticosteroid. Intern Med 2003;42:565-570

21 Lok SS, Smith E, Doran HM, Sawyer R, Yonan N, Egan JJ: Idiopathic pulmonary fibrosis and cyclosporine: a lesson from singlelung transplantation. Chest 1998; 114: 1478-1481.

22 Homma S, Kawabata M, Kishi K, Tsuboi E, Narui K, Nakatani T, Matsushita H, Kurosaki A, Nakata K: Cyclosporin A treatment of interstitial pneumonia (in Japanese). Nihon Kokyuki Gakkai Zasshi 2003;41:427433.

23 Wahidi MM, Ravenel J, Palmer SM, McAdams HP: Progression of idiopathic pulmonary fibrosis in native lungs after single lung transplantation. Chest 2002;121:2072-2076.

24 Trulock EP, Edwards LB, Taylor DO, Boucek MM, Mohacsi PJ, Keck BM, Hertz MI: The Registry of the International Society for Heart and Lung Transplantation: Twentieth Official adult lung and heart-lung transplant report - 2003. J Heart Lung Transplant 2003; 22:625-635. 
25 American Thoracic Society/European Respiratory Society International Multidisciplinary Consensus Classification of the Idiopathic Interstitial Pneumonias: This joint statement of the American Thoracic Society (ATS), and the European Respiratory Society (ERS) was adopted by the ATS board of directors, June 2001 and by the ERS Executive Committee, June 2001. Am J Respir Crit Care Med 2002;165:277-304.

26 Crystal RG, Bitterman PB, Mossman B, Schwarz MI, Sheppard D, Almasy L, Chapman HA, Friedman SL, King TE Jr, Leinwand LA, Liotta L, Martin GR, Schwartz DA, Schultz GS, Wagner CR, Musson RA: Future research directions in idiopathic pulmonary fibrosis: summary of a National Heart, Lung, and Blood Institute working group. Am J Respir Crit Care Med 2002;166:236-246.
27 Alton EW, Johnson M, Turner-Warwick M Advanced cryptogenic fibrosing alveolitis: preliminary report on treatment with cyclosporin A. Respir Med 1989;83:277-279.

28 Akira M, Sakatani M, Ueda E: Idiopathic pulmonary fibrosis: progression of honeycombing at thin-section CT. Radiology 1993; 189:687-691.

29 Terriff BA, Kwan SY, Chan-Yeung MM, Muller NL: Fibrosing alveolitis: chest radiography and $\mathrm{CT}$ as predictors of clinical and functional impairment at follow-up in $26 \mathrm{pa}$ tients. Radiology 1992;184:445-449.
30 Wells AU, Hansell DM, Rubens MB, Cullinan $\mathrm{P}$, Black CM, du Bois RM: The predictive value of appearances on thin-section computed tomography in fibrosing alveolitis. Am Rev Respir Dis 1993;148:1076-1082.

31 Nagao T, Nagai S, Hiramoto Y, Hamada K, Shigematsu M, Hayashi M, Izumi T, Mishima M: Serial evaluation of high-resolution computed tomography findings in patients with idiopathic pulmonary fibrosis in usual interstitial pneumonia. Respiration 2002;69: 413-419.

32 Nagao T, Nagai S, Kitaichi M, Hayashi M, Shigematsu M, Tsutsumi T, Satake N, Izumi T: Usual interstitial pneumonia: idiopathic pulmonary fibrosis versus collagen vascular diseases. Respiration 2001;68:151-159. 